\title{
Ovarian tissue cryopreservation in a patient with breast cancer during pregnancy: a case report
}

Jiaojiao Cheng ${ }^{1}$, Xiangyan Ruan ${ }^{1,2^{*}} \mathbb{0}$, Juan Du ${ }^{1}$, Fengyu Jin ${ }^{1}$, Yanglu Li ${ }^{1}$, Xiaowei Liu ${ }^{3}$, Husheng Wang ${ }^{1}$, Muqing $\mathrm{Gu}^{1}$ and Alfred O. Mueck ${ }^{1,2}$

\begin{abstract}
Background: Fertility preservation using ovarian tissue cryopreservation (OTC) in patients with certain diseases, especially those needing chemo- or radiotherapy, is becoming routine in various Western countries. Our hospital is the first and until now the only centre in China to use this method. The question of whether treatment of breast cancer during pregnancy ( $\mathrm{PrBC}$ ) should be similar to non-pregnant young patients with breast cancer is controversial. To our knowledge, this is the first report worldwide to use OTC as fertility preservation for PrBC.
\end{abstract}

Case presentation: During the 29th week of pregnancy, a 24-year-old woman underwent needle aspiration cytology of a left breast tumour. Ultrasound and cytology revealed BI-RADS 4a grade. Oncologists recommended termination of the pregnancy. Caesarean section was performed at week 32, and ovarian tissue samples were collected for OTC to preserve fertility and ovarian endocrine function. Twenty-three ovarian cortex slices were cryopreserved. It is estimated that 13,000 follicles were cryopreserved. Breast nodules and sentinel lymph node biopsy suggested invasive micropapillary carcinoma. Neoadjuvant chemotherapy was started within 1 week after diagnosis. After six courses of neoadjuvant chemotherapy, targeted drug therapy and goserelin acetate, left mastectomy and left axillary lymph node dissection were performed. In total, 23 doses of radiotherapy, eight trastuzumab targeted therapy treatments, and 17 pertuzumab + trastuzumab double targeted therapy treatments were performed after breast cancer surgery. Until now, more than 2 years after delivery, the ovarian function still is good, and no signs of a negative impact of OTC have been observed. Goserelin acetate injections, administered every 28 days, are planned to last for the next 5 years. In addition, endocrine therapy with anastrozole was started after breast cancer surgery and also is scheduled for 5 years.

Conclusion: OTC for fertility preservation in patients with $\operatorname{PrBC}$ does not delay breast surgery, radiotherapy or chemotherapy, which is essential for effective treatment of breast cancer. We assess this method as a promising fertility preservation method which was used here for the first time worldwide in a patient who developed breast cancer during pregnancy.

Keywords: Breast cancer during pregnancy, ovarian tissue cryopreservation, fertility preservation, ovarian function

\footnotetext{
*Correspondence: ruanxiangyan@ccmu.edu.cn

1 Department of Gynecological Endocrinology, Beijing Obstetrics and Gynecology Hospital, Capital Medical University, Beijing Maternal and Child Health Care Hospital, No. 251, Yaojiayuan Road, Chaoyang District, Beijing 100026, People's Republic of China

Full list of author information is available at the end of the article
}

\section{Background}

In 2020, there were 2.26 million new cases of female breast cancer worldwide, far exceeding other types of female cancers, accounting for about $24.5 \%$ of female cancers [1]. Breast cancer during pregnancy $(\operatorname{PrBC})$ occurring as primary breast cancer diagnosed during original author(s) and the source, provide a link to the Creative Commons licence, and indicate if changes were made. The images or other third party material in this article are included in the article's Creative Commons licence, unless indicated otherwise in a credit line to the material. If material is not included in the article's Creative Commons licence and your intended use is not permitted by statutory regulation or exceeds the permitted use, you will need to obtain permission directly from the copyright holder. To view a copy of this licence, visit http://creativecommons.org/licenses/by/4.0/. The Creative Commons Public Domain Dedication waiver (http://creativeco mmons.org/publicdomain/zero/1.0/) applies to the data made available in this article, unless otherwise stated in a credit line to the data. 
pregnancy [2], accounts for about $4 \%$ of breast cancer cases in women under the age of 45 [3]. The incidence of $\operatorname{PrBC}$ is estimated to be about 1 in 3000 pregnancies [3]. Breast cancer during the postpartum period (PPBC), arising within 5-10years after delivery, accounts for an estimated $35-55 \%$ of all breast cancer cases in women under 45 years of age [4]. The incidence of pregnancyrelated breast cancer has increased significantly over the past 10 years [5], especially in developed countries. It may be related to the postponement of the age of first pregnancy and the continued increase in the incidence of young breast cancer [6]. With the development of early diagnosis and treatment strategies for breast cancer, the disease-free and overall survival rate of patients with breast cancer have been greatly improved [7]. However, compared with unaffected women, the fertility rate of breast cancer patients decreases significantly about $40-67 \%$ after diagnosis and treatment. More and more attention has been paid to the effects of breast cancer chemotherapy, radiotherapy, and endocrine therapy on the quality of life and fertility of breast cancer patients [8].

At present, fertility preservation strategies mainly include embryo and oocyte cryopreservation, ovarian tissue cryopreservation (OTC), in vitro maturation (IVM), and gonadotropin-releasing hormone analogue (GnRHa) therapy during chemotherapy [9]. However, to our knowledge, there are no reports about OTC in patients with PrBC. This report described performing OTC in a young patient with $\operatorname{PrBC}$, which could provide a new understanding for clinicians and the first evidence for fertility preservation in patients with PrBC.

\section{Case presentation}

The case describes a 26-year-old Chinese lady who was pregnant 2 years ago. At 15 weeks' 15 gestation, she felt a solid lump in her left breast. Physical examination showed that the left breast mass was the size of a peanut, with milk overflow, no tenderness, and no apparent depression or bumps on the breast surface. Breast ultrasound showed mammary gland hyperplasia, and the low echo of the left breast, $12 * 8 \mathrm{~mm}, 11 * 7 \mathrm{~mm}$, breast imaging reporting and data system (BI-RADS) 4a grade. The oncologist suggested re-examination after 3 months. The patient noticed that the breast mass gradually increased, so she saw a doctor again in a large grade 3A hospital. Needle aspiration cytology of the left breast tumour was performed in March 14, 2019, and cancer cells were detected. Using breast ultrasound, a solid nodule was seen in the lower left breast quadrant, $18^{*} 13 \mathrm{~mm}$, clear boundary, lobulated, BI-RADS 3 grade. A solid cystic nodule, $10 * 8 \mathrm{~mm}$, was found, and a solid area could be seen in it, range about $4 * 3 \mathrm{~mm}$, BI-RADS $4 \mathrm{a}$. Oncologists recommended that the patient should undergo termination of the pregnancy.

Caesarean section was performed at 32 weeks and 4 days of pregnancy in the Beijing Obstetrics and Gynecology Hospital, Capital Medical University, and a healthy baby boy was delivered. At the same time as the caesarean section, the ovarian tissue biopsy was taken for OTC to preserve fertility and ovarian function. Half an ovary was removed from one side, and 1/3 of the ovary from the other side. The condition of the fresh ovarian tissue was good, with a corpus luteum and rich blood vessels.

The ovarian tissue was successfully processed and slow-programmatically cryopreserved in ovarian tissue cryobank, and fresh cortex viability and morphology assessment was performed. The methods description was consistent with the previously published article $[10,11]$. A total of 23 pieces of ovarian cortex were frozen. The number of follicles in a round cortical piece of $2 \mathrm{~mm}$ is about 45, and it is estimated that 13,000 follicles were frozen for this patient. The images of follicular viability are shown in Fig. 1, and the images of HE staining in the cortex are shown in Fig. 2.

A biopsy of the left breast tumour was performed on April 18, 2019. Pathological findings showed (breast tissue) invasive micropapillary carcinoma of the breast, immunohistochemical results: estrogen receptor (ER) (weak-medium positive, 10\%), progesterone receptor (PR) (-), androgen receptor (AR) (weak-medium positive, $80 \%$ ), human epidermal growth factor receptor 2 (HER-2) $(3+)$. Ki-67 (index 30\%), p53 (+), cytokeratin 14 (CK14) (-), D2-40 (-), epithelial membrane antigen (EMA) (+), CK5/6 (-), epidermal growth factor receptor (EGFR) (-), synaptophysin (Syn) (-), chromogranin A (CgA) (-). A left axillary sentinel lymph node biopsy was performed on April 24, 2019. Pathology showed that the metastatic carcinoma of the lymph node (left sentinel) (2 positives in 3) and the isolated tumour cells could be seen in the capsule of the other lymph node.

Neoadjuvant chemotherapy was administered prior to breast surgery. The first chemotherapy regimen was docetaxel $120 \mathrm{mg}$, epirubicin $110 \mathrm{mg}$, and cyclophosphamide $900 \mathrm{mg}$, q3w. Injections of $3.6 \mathrm{mg}$ goserelin acetate every 28 days were given starting after the first course of chemotherapy, planned to continue for 5 years. No menstruation occurred after the start of chemotherapy. According to the immunohistochemistry results, the 2nd-6th chemotherapy regimen was adjusted as follows: docetaxel $110 \mathrm{mg}$ and carboplatin $500 \mathrm{mg}$. Targeted therapy was administered with trastuzumab, the first dose was $17 \mathrm{ml}$, which was then changed to $13 \mathrm{ml}$. Six doses of targeted therapy were administered before breast surgery.

Ultrasound examination of breast and axillary lymph nodes before breast surgery showed that low echo was 


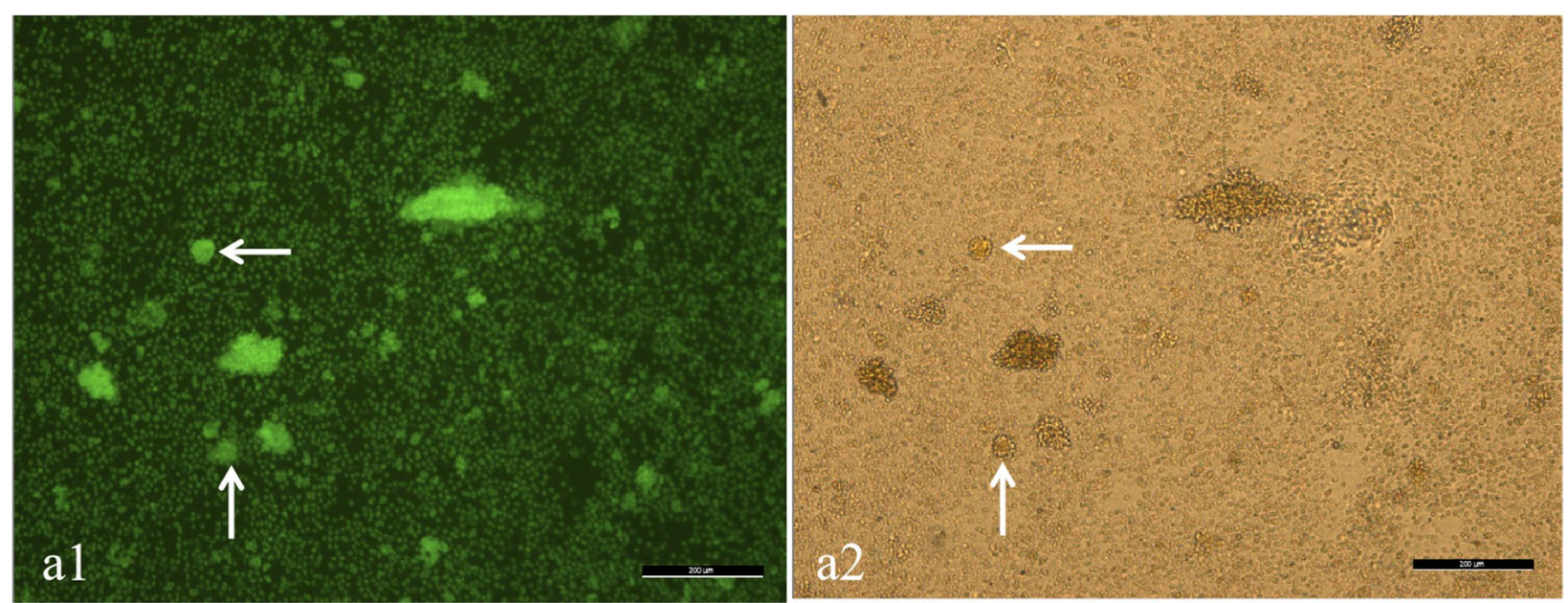

Fig. 1 Typical pictures of follicles in the fresh ovarian cortex. a1 is the image under the fluorescence microscope, and a2 is the image under the optical microscope. The white arrow refers to the follicles. bar $=200 \mu \mathrm{m}$
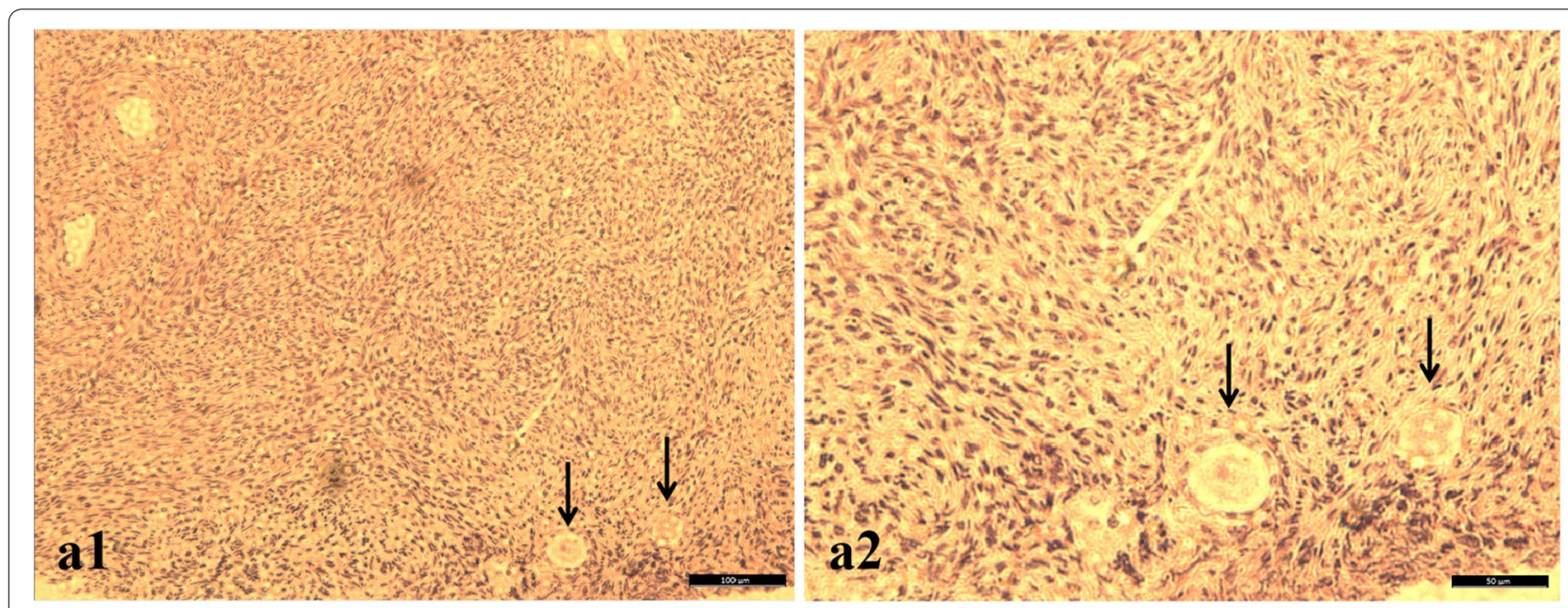

Fig. 2 Typical HE staining images of follicles in the fresh ovarian cortex. The black arrow refers to the follicle. In a1, bar = $100 \mu \mathrm{m}$; in a2, bar = 50 $\mu \mathrm{m}$

seen at the edge of the gland in the direction of $6-7$ o'clock in the left breast, $19 * 16 * 8 \mathrm{~mm}$. The boundary was unclear, and a dotted strong echo was diffused in the left breast, BI-RADS 6.

Simple left mastectomy (preserving nipple-areola) and left axillary lymph node dissection were performed on September 10, 2019. Left breast reconstruction + acellular allogenic dermis implantation + dilator implantation was performed after breast surgery. Pathological report: a few invasive carcinomas in the (left) breast (the largest $7 \mathrm{~mm}$ ), and a vascular tumour thrombus, the bottom cutting edge not special, lymph nodes showing chronic inflammation (left axilla 0/18). Immunohistochemical results showed: ER (weak positive, 10\%), PR (-), AR (weak positive, 90\%), Her-2 $(3+)$, Ki-67 (index25\%), p53 (scattered +), EGFR (-), CK14 (-), CK5/6 (-), p63 (-), CgA (-), Syn (-), EMA (+).

After breast surgery, fixed-field intensity-modulated radiation therapy was performed with a $6 \mathrm{MV}-\mathrm{X}$ line. $95 \%$ of the plan clinical tumour volume included left upper and lower clavicle, chest wall, dose $46 \mathrm{~Gy} / 23$ times (2Gy/f), $5 \mathrm{f} / \mathrm{w}$, filler bolus $0.5 \mathrm{~cm}$.

Fourteen courses of trastuzumab were administered after surgery, followed by about 17 courses of pertuzumab + trastuzumab $13 \mathrm{ml}$ double targeted therapy for 1 year. After breast surgery, goserelin acetate was continued every 28 days, and is planned to last for 5 
years. Endocrine therapy using anastrozole, a potent aromatase inhibitor, is also scheduled to last for 5 years.

The serum hormone levels before OTC and 1 year, 1.5 years, 2 years, and 2.2 years after OTC are shown in Table 1. At present, it seems that the AMH level of the patients is in the normal range, and the levels of FSH, LH, and E2 are all at a low level.

\section{Discussion and Conclusion}

A 26-year-old woman in the third trimester of pregnancy was diagnosed with PrBC more than 2 years ago and underwent caesarean section at 32 weeks and 4 days to terminate the pregnancy. Subsequently, the patient underwent chemotherapy, radiotherapy, targeted therapy, breast cancer surgery, and long-term endocrine therapy. During caesarean section, ovarian tissue samples were collected and OTC was performed to preserve fertility and ovarian function, without additional ovarian tissue biopsy surgery. This technique for fertility preservation avoids ovarian hyper-stimulation, and there is no need to delay follow-up anti-cancer treatment. For this patient, the risk of premature ovarian insufficiency (POI) in the future is high, but her survival rate is also very high. Only one child was born, and the patient still is young and wishes to preserve ovarian function and fertility.

$\operatorname{PrBC}$ should be regarded as an independent entity to breast cancer occurring during the postpartum period (PPBC). The treatment of PrBC is individualized according to gestational age and considers the safety of the foetus. The treatment of PPBC does not need to consider these issues. The histopathological and immunohistochemical results of tumours in PrBC patients seem to be similar to those in young non-pregnant breast cancer patients. High estrogen and progesterone levels during pregnancy may stimulate the proliferation of breast cancer cells in PrBC patients. However, the prognosis does not seem to differ from non-pregnant patients of the same age and stage [3, 4]. As with the patient in this study, the current outcome is good. Therefore, the biological characteristics of the tumour are more likely to be determined by the age at the time of diagnosis than by pregnancy.
In 2013, the American Society of Clinical Oncology conducted a comparative study of 311 patients with $\operatorname{PrBC}$ and 865 patients with non-pregnancy-related breast cancer [12]. It was found that the overall survival rate of patients with $\operatorname{PrBC}$ was similar to that of patients with non-pregnancy-related breast cancer. This information is essential when the PrBC patient is consulted and supports the start of treatment while pregnancy can continue. For our case, the pregnancy was terminated after confirmation of the diagnosis according to the oncologists' recommendations, i.e. anti-cancer treatment was not started during pregnancy.

The 5-year relative survival rate of breast cancer patients is about $90 \%$ [13]. More than $50 \%$ of young women with breast cancer wish to become pregnant after treatment [14]. It is reported that their chances of pregnancy are $40-67 \%$ lower than that of the general population [15]. Some studies have reported that the live birth rate for breast cancer patients after treatment is less than $5 \%[16,17]$. Recently, a large sample study showed that in breast cancer patients with and without fertility preservation, the cumulative incidence of live births after 5 years of breast cancer diagnosis was 19.4 and $8.6 \%$, respectively, and 40.7 and $15.8 \% 10$ years later [18]. The research on pregnancy safety after breast cancer treatment is complex, and randomized controlled trials are impossible, so the evidence to guide clinical practice is limited.

The best time to conceive after the diagnosis of breast cancer is still inconclusive. The main concern is the recurrence of cancer and the interruption of endocrine therapy. ER-negative patients should be delayed for 2-3 years according to the prognosis. Positive patients can discuss whether to discontinue endocrine treatment after 3 years, but patients must be informed of the lack of data support [19]. One large meta-analysis [20] found that post-breast cancer pregnancy had no adverse effect on survival. Women who became pregnant after breast cancer had even higher survival rates than non-pregnant breast cancer patients [21].

Patients with $\operatorname{PrBC}$ received chemotherapy during pregnancy and post-natal chemotherapy, and an observational study reported no difference in survival rate

Table 1 Hormone levels of before and after cryopreservation

\begin{tabular}{llllll}
\hline & $\begin{array}{l}\mathbf{2 0 1 9 . 0 4 . 0 8} \text { (before } \\
\text { OTC) }\end{array}$ & $\begin{array}{l}\mathbf{2 0 2 0 . 0 5 . 0 8 ~ ( 1 ~ y e a r ~ a f t e r ~} \\
\text { OTC) }\end{array}$ & $\begin{array}{l}\mathbf{2 0 2 0 . 1 0 . 1 2} \text { (1.5 years } \\
\text { after OTC) }\end{array}$ & $\begin{array}{l}\mathbf{2 0 2 1 . 0 3 . 1 7} \text { (2 years } \\
\text { after OTC) }\end{array}$ & $\begin{array}{l}\mathbf{2 0 2 1 . 0 6 . 1 8} \\
(\mathbf{2 . 2} \text { years after } \\
\text { OTC) }\end{array}$ \\
\hline $\mathrm{AMH}(\mathrm{ng} / \mathrm{ml})$ & 2.73 & 1.18 & 1.3 & 2.54 & 3.70 \\
$\mathrm{FSH}(\mathrm{IU} / \mathrm{L})$ & 0 & 4.05 & 6.08 & 3.66 & 4.64 \\
$\mathrm{LH}(\mathrm{IU} / \mathrm{L})$ & 0 & 1.46 & 1.31 & 1.03 & 0.39 \\
$\mathrm{E} 2(\mathrm{pg} / \mathrm{ml})$ & 15,000 & 11.8 & 11.8 & 33.67 & 19.37 \\
\hline
\end{tabular}

$A M H$ anti-müllerian hormone, FSH follicle-stimulating hormone, $L H$ luteinizing hormone, E2 estradiol, OTC ovarian tissue cryopreservation 
[22]. Chemotherapy during pregnancy is generally carried out in the third trimester of pregnancy, and there is no increase in the rate of congenital malformations. The available data confirm that the mother and foetus are safe whilst using breast cancer treatment during pregnancy [22]. Because preterm delivery is closely related to adverse events, full-term delivery seems to be the most important.

The degree of ovarian function damage caused by breast cancer chemotherapy is related to the patient's age, chemotherapy type, dose, and duration [23]. Among the commonly used chemotherapeutic drugs, alkylating agents have the strongest gonadal toxicity, followed by platinum, paclitaxel, anthracycline, and so on. Some patients may have temporary or permanent amenorrhea during chemotherapy. $40-60 \%$ of women under 40 years old will have amenorrhea, and more than $80 \%$ of women over 40 years old will have amenorrhea. Although some patients' menstruation can recover after chemotherapy, ovarian function is still impaired. This suggests that menstruation does not necessarily mean giving birth [24, 25]. It is recommended that fertility preservation strategies should be taken as far as possible for patients who still have fertility wishes in the future before the start of chemotherapy [26].

Radiotherapy is an essential part of comprehensive breast cancer treatment. It is an important measure to reduce the recurrence and prolong the survival of patients undergoing breast-conserving surgery and highrisk mastectomy [27]. In breast cancer patients receiving standard whole breast radiotherapy, 2.1-7.6cGy $(1 \mathrm{~Gy}=100 \mathrm{cGy})$ reaches the uterus and ovaries through the internal scattering of 50Gy radiation dose to the breast [28]. Radiotherapy is not recommended for PrBC but can be chosen according to the condition after stopping breastfeeding at the end of pregnancy [29].

Endocrine therapy refers to drugs to block the promoting effect of sex hormones on breast cancer cells according to the expression of ER and PR in breast cancer tissue [30]. Anastrozole is a potent, selective aromatase inhibitor of triazole, blocking estrogen biosynthesis by inhibiting aromatase [31]. Estrogen is the main factor that stimulates the growth of breast cancer cells. Although endocrine therapy has no reproductive toxicity, endocrine treatment lasts for 5-10years, and the ovarian function of patients continues to decrease with age. Therefore, breast cancer patients with fertility needs are recommended fertility preservation before endocrine therapy [7].

Embryo cryopreservation is the most widely used and technically perfect fertility preservation strategy in the clinic, suitable for married women after puberty [32]. Two aspects are worth paying attention to 1) due to a series of procedures such as ovulation stimulation, in vitro fertilization, and embryo cryopreservation, the treatment of breast cancer may be delayed for about 2 weeks; 2 ) the hyper-physiological dose of estrogen caused by ovulation stimulation maybe promote the development of breast cancer. There has been a report [33] of fertility preservation with random-start controlled ovarian stimulation and embryo cryopreservation for early pregnancy-associated breast cancer.

Oocyte cryopreservation also is suitable for unmarried women after puberty. It is recommended that women $<38$ years old freeze 15-20 MII stage oocytes, the chance of at least one live birth is $70-80 \%$. For $38-40$-year-old women, if 25-30 MII stage oocytes are frozen, the chance of at least one live birth is $65-75 \%$ [34]. IVM can reduce ovarian stimulation, avoid a high estrogen state, and be combined with OTC [35]. Although it is estimated that more than 5000 babies have been born through IVM technology worldwide [36], IVM is still considered an experimental technology by the American Society of Reproductive Medicine (ASRM) [37].

The OTC technique requires minimally invasive surgery to remove ovarian tissue before gonadotoxicity treatment, without the need for ovarian stimulation to obtain oocytes. It is the only fertility preservation method for patients who cannot delay anti-cancer treatment [38, 39]. More than 200 babies have been born worldwide after OTC and transplantation [40], and in 2019 the ASRM stated that this technique is no longer experimental [41]. The ovarian tissue cryobank of Beijing Obstetrics and Gynecology Hospital, the first and until now the only one in China [42], has successfully cryopreserved more than 370 cases of ovarian tissue up to now, of which $10.8 \%$ are breast cancer patients. A total of 10 cases of ovarian tissue were transplanted [11, 43], including 1 case of breast cancer with negative ER, PR, and HER2 $(3+)$. The ovarian function was recovered after transplantation. One patient with myelodysplastic syndrome (MDS) successfully became pregnant naturally [44] after ovarian transplantation and a healthy baby girl was born (article under review). The timing of ovarian tissue transplantation in this breast cancer patient should be discussed with a breast cancer specialist. The main indicators are as follows [42]: 1) multidisciplinary cooperation is needed; 2) the patient is disease-free and endocrine therapy at least 2 years or can be stopped and stopped at least 3-6 months; 3 ) ovarian function failure; 4) there is a desire for fertility.

Breast cancer is one of the most common indications for OTC and transplantation. In five major centres in Europe, of 285 transplant patients, 96 were breast cancer patients and 7 had relapsed (7.3\%) [45]. Breast cancer itself is a known disease with a risk of 
recurrence [46]. At the time of breast cancer diagnosis, young age is associated with an increased risk of recurrence [47], while patients who receive OTC are usually very young and almost all are under the age of 40 . All relapses were dependent of the primary disease and had nothing to do with ovarian tissue transplantation. All relapses were far away from the transplant site, and most of them were close to the location of the primary cancer. The recurrence rate of $7.3 \%$ is similar to that of breast cancer women under 40 years old observed in the literature, with a local recurrence rate of $10 \%$ [48] and a 10 -year recurrence rate of $4-8.7 \%$ [46]. Regarding transplanting ovarian tissue from breast cancer patients, it should be kept in mind that they are still cancer patients in remission.

\section{Conclusion}

Ovarian tissue cryopreservation for fertility preservation in patients with PrBC does not delay breast surgery, radiotherapy, or chemotherapy which is essential for effective treatment of breast cancer. Until now, more than 2 years after delivery, we do not see any signs of a negative impact of performing OTC at the same time as caesarean section, and subsequently receiving chemotherapy, radiotherapy, targeted therapy, breast cancer surgery, and endocrine therapy. At present, the patient's ovarian function is still good. Although long-term results and especially the results after retransplantation of ovarian tissue still are missing, we assess this method, which to date has only been performed in our hospital in China, as a promising fertility preservation method for patients who develop breast cancer during pregnancy.

\section{Abbreviations \\ OTC: Ovarian tissue cryopreservation; POI: Premature ovarian insufficiency; PrBC: Breast cancer occurs during pregnancy; PPBC: Breast cancer occurs dur- ing the postpartum period; IVM: In vitro maturation; GnRHa: Gonadotropin- releasing hormone analogue; BI-RADS: Breast imaging reporting and data sys- tem; ER: Estrogen receptor; PR: Progesterone receptor; AR: Androgen receptor; HER-2: Human epidermal growth factor receptor 2; EMA: Epithelial membrane antigen; EGFR: Epidermal growth factor receptor; Syn: Synaptophysin; CgA: Chromogranin A; ASRM: American society of reproductive medicine; FSH: Follicle stimulating hormone; $\mathrm{LH}$ : Luteinizing hormone; $\mathrm{AMH}$ : Anti-müllerian hormone; E2: Estradiol; MDS: Myelodysplastic syndrome.}

\section{Acknowledgments}

For establishing the first ovarian tissue cryobank in China, the authors thank Prof. Markus Montag (International Reprolab Consulting ilabcomm GmbH, FertiProtekt Network, Germany) and Dr. Jana Liebenthron (University Women's Hospital, Duesseldorf, Germany) for their generous help and continuing support.

\section{Authors' contributions}

$J C$ wrote the original draft and revised the manuscript. XR acquired the medical report and data from the patient, project, and funds leader. JD, FJ, and YL cryopreserved the ovarian tissue. MG cryopreserved the ovarian tissue and follow-up patients. XL performed the caesarean section and ovarian tissue biopsy. HW transported the ovarian tissue to cryobank. AM guided the implementation of the project and revised the final manuscript. All authors read and approved the final paper.

\section{Funding}

This study was supported by Natural Science Foundation of Beijing (7202047); Beijing Capital Foundation for Medical Science Development and Research (2020-2-2112); Beijing Municipal Administration of Hospitals' Ascent Plan (DFL20181401).

\section{Availability of data and materials}

All the generated data are included in this article.

\section{Declarations}

\section{Ethics approval and consent to participate}

This study was approved by the Beijing Obstetrics and Gynecology Hospital, Capital Medical University, China ethics committee on 15th March 2017 (Protocol number 2017-KY-020-01).

\section{Consent for publication}

The patient provided written informed consent for the publication of this case report.

\section{Competing interests}

The authors declare that they have no competing interests.

\section{Author details}

1Department of Gynecological Endocrinology, Beijing Obstetrics and Gynecology Hospital, Capital Medical University, Beijing Maternal and Child Health Care Hospital, No. 251, Yaojiayuan Road, Chaoyang District, Beijing 100026, People's Republic of China. ${ }^{2}$ Department for Women's Health, University Women's Hospital and Research Centre for Women's Health, University of Tuebingen, 72076 Tuebingen, Germany. ${ }^{3}$ Department of Obstetrics, Beijing Obstetrics and Gynecology Hospital, Capital Medical University, Beijing Maternal and Child Health Care Hospital, Beijing 100026, China.

Received: 18 August 2021 Accepted: 27 November 2021

Published online: 12 December 2021

\section{References}

1. Sung H, Ferlay J, Siegel RL, Laversanne M, Soerjomataram I, Jemal A, et al. Global Cancer Statistics 2020: GLOBOCAN Estimates of Incidence and Mortality Worldwide for 36 Cancers in 185 Countries. CA Cancer J Clin. 2021;71(3):209-49.

2. Amant F, Loibl S, Neven P, Calsteren KV. Breast cancer in pregnancy, Lancet. 2012;379(9815):570-9.

3. Loibl S, von Minckwitz G, Gwyn K, Ellis P, Blohmer JU, Schlegelberger B, et al. Breast carcinoma during pregnancy. International recommendations from an expert meeting. Cancer. 2006;106(2):237-46.

4. Amant $F$, Lefrere $H$, Borges VF, Cardonick $E$, Lambertini $M$, Loibl S, et al. The definition of pregnancy-associated breast cancer is outdated and should no longer be used. Lancet Oncol. 2021;22(6):753-4.

5. Andersson TM, Johansson A, Hsieh CC, Cnattingius S, Lambe M. Increasing incidence of pregnancy-associated breast cancer in Sweden. Obstet Gynecol. 2009;114(3):568-72.

6. Wang B, Yang Y, Jiang Z, Zhao J, Mao Y, Liu J, et al. Clinicopathological characteristics, diagnosis, and prognosis of pregnancy-associated breast cancer. Thorac Cancer. 2019;10(5):1060-8.

7. Warner E, Glass K, Foong S, Sandwith E. Update on fertility preservation for younger women with breast cancer. CMAJ. 2020;192(35):E1003-9.

8. von Wolff M, Dittrich R, Liebenthron J, Nawroth F, Schüring AN, Bruckner $\mathrm{T}$, et al. Fertility-preservation counselling and treatment for medical reasons: data from a multinational network of over 5000 women. Reprod BioMed Online. 2015;31(5):605-12.

9. Shah NM, Scott DM, Kandagatla P, Moravek MB, Cobain EF, Burness ML, et al. Young Women with Breast Cancer: Fertility Preservation Options 
and Management of Pregnancy-Associated Breast Cancer. Ann Surg Oncol. 2019;26(5):1214-24.

10. Li Y, Ruan X, Liebenthron J, Montag M, Zhou Q, Kong W, et al. Ovarian tissue cryopreservation for patients with premature ovary insufficiency caused by cancer treatment: optimal protocol. Climacteric. 2019;22(4):383-9.

11. Ruan X, Cheng J, Korell M, Du J, Kong W, Lu D, et al. Ovarian tissue cryopreservation and transplantation prevents iatrogenic premature ovarian insufficiency: first 10 cases in China. Climacteric. 2020;23(6):574-80.

12. Amant $F$, von Minckwitz G, Han SN, Bontenbal M, Ring AE, Giermek J, et al. Prognosis of women with primary breast cancer diagnosed during pregnancy: results from an international collaborative study. J Clin Oncol. 2013:31(20):2532-9.

13. Coleman MP, Forman D, Bryant H, Butler J, Rachet B, Maringe C, et al. Cancer survival in Australia, Canada, Denmark, Norway, Sweden, and the UK, 1995-2007 (the International Cancer Benchmarking Partnership): an analysis of population-based cancer registry data. Lancet. 2011:377(9760):127-38.

14. Azim HJ, Peccatori FA, de Azambuja E, Piccart MJ. Motherhood after breast cancer: searching for la dolce vita. Expert Rev Anticancer Ther. 2011;11(2):287-98.

15. Gerstl B, Sullivan E, Ives A, Saunders C, Wand H, Anazodo A. Pregnancy Outcomes After a Breast Cancer Diagnosis: A Systematic Review and Meta-analysis. Clin Breast Cancer. 2018;18(1):e79-88.

16. Pagani O, Partridge A, Korde L, Badve S, Bartlett J, Albain K, et al. Pregnancy after breast cancer: if you wish, ma'am. Breast Cancer Res Treat. 2011:129(2):309-17.

17. Lambertini M, Del ML, Pescio MC, Andersen CY, Azim HA Jr, Peccatoriet $F A$, et al. Cancer and fertility preservation: international recommendations from an expert meeting. BMC Med. 2016;14:1.

18. Marklund A, Lundberg FE, Eloranta S, et al. Reproductive Outcomes After Breast Cancer in Women With vs Without Fertility Preservation. JAMA Oncol. 2021;7(1):86-91.

19. Margulies AL, Selleret L, Zilberman S, et al. Pregnancy after cancer: for whom and when? Bull Cancer. 2015;102(5):463-9.

20. Azim HJ, Santoro L, Pavlidis N, Hedayati E, Pettersson K, RodriguezWallberg KA. Safety of pregnancy following breast cancer diagnosis: a meta-analysis of 14 studies. Eur J Cancer. 2011:47(1):74-83.

21. Christinat A, Pagani O. Fertility after breast cancer. Maturitas. 2012;73(3):191-6

22. Loibl S, Han SN, von Minckwitz G, Bontenbal M, Ring A, Giermek J, et al. Treatment of breast cancer during pregnancy: an observational study. Lancet Oncol. 2012;13(9):887-96.

23. Levine JM, Kelvin JF, Quinn GP, Gracia CR. Infertility in reproductive-age female cancer survivors. Cancer. 2015;121(10):1532-9.

24. Lambertini M, Goldrat O, Clatot F, Demeestere I, Awada A. Controversies about fertility and pregnancy issues in young breast cancer patients: current state of the art. Curr Opin Oncol. 2017;29(4):243-52.

25. Abusief ME, Missmer SA, Ginsburg ES, Weeks JC, Partridge AH. The effects of paclitaxel, dose density, and trastuzumab on treatment-related amenorrhea in premenopausal women with breast cancer. Cancer. 2010;116(4):791-8.

26. Waks AG, Partridge AH. Fertility Preservation in Patients With Breast Cancer: Necessity, Methods, and Safety. J Natl Compr Cancer Netw. 2016;14(3):355-63.

27. Loibl S, Poortmans P, Morrow M, Denkert C, Curigliano G. Breast cancer. Lancet. 2021;397(10286):1750-69.

28. Bajpai J, Majumdar A, Satwik R, Rohatgi N, Jain V, Gupta D. Practical consensus recommendations on fertility preservation in patients with breast cancer. South Asian J Cancer. 2018;7(2):110-4.

29. Kal HB, Struikmans H. Radiotherapy during pregnancy: fact and fiction. Lancet Oncol. 2005;6(5):328-33.

30. Marti C, Sanchez-Mendez JI. The Present and Future of Neoadjuvant Endocrine Therapy for Breast Cancer Treatment. Cancers (Basel). 2021;13(11):2538.

31. Masuda N, Sagara Y, Kinoshita T, Iwata H, Nakamura S, Yanagita Y, et al. Neoadjuvant anastrozole versus tamoxifen in patients receiving goserelin for premenopausal breast cancer (STAGE): a double-blind, randomised phase 3 trial. Lancet Oncol. 2012;13(4):345-52.
32. Oktay K, Harvey BE, Partridge AH, Quinn GP, Reinecke J, Taylor HS, et al. Fertility Preservation in Patients With Cancer: ASCO Clinical Practice Guideline Update. J Clin Oncol. 2018;36(19):1994-2001.

33. Pereira N, Kligman I, Hunt R, Kopparam R, Wahmann B, Rosenwaks Z. Fertility preservation with random-start controlled ovarian stimulation and embryo cryopreservation for early pregnancy-associated breast cancer. Gynecol Endocrinol. 2019;35(3):214-6.

34. Doyle JO, Richter KS, Lim J, Stillman RJ, Graham JR, Tucker MJ. Successful elective and medically indicated oocyte vitrification and warming for autologous in vitro fertilization, with predicted birth probabilities for fertility preservation according to number of cryopreserved oocytes and age at retrieval. Fertil Steril. 2016;105(2):459-66.

35. Telfer EE, Andersen CY. In vitro growth and maturation of primordial follicles and immature oocytes. Fertil Steril. 2021;115(5):1116-25.

36. Yang ZY, Chian RC. Development of in vitro maturation techniques for clinical applications. Fertil Steril. 2017;108(4):577-84.

37. Practice Committees of the American Society for Reproductive Medicine, the Society of Reproductive Biologists and Technologists, and the Society for Assisted Reproductive Technology. In vitro maturation: a committee opinion. Fertil Steril. 2021;115(2):298-304.

38. Fabbri R, Vicenti R, Magnani V, Pasquinelli G, Macciocca M, Parazza I, et al. Cryopreservation of ovarian tissue in breast cancer patients: 10 years of experience. Future Oncol. 2012;8(12):1613-9.

39. Donnez J, Dolmans MM. Fertility preservation in men and women: Where are we in 2021? Are we rising to the challenge? Fertil Steril. 2021;115(5):1089-90.

40. Dolmans MM, Falcone T, Patrizio P. Importance of patient selection to analyze in vitro fertilization outcome with transplanted cryopreserved ovarian tissue. Fertil Steril. 2020;114(2):279-80.

41. Practice Committee of the American Society for Reproductive Medicine. Fertility preservation in patients undergoing gonadotoxic therapy or gonadectomy: a committee opinion. Fertil Steril. 2019;112(6):1022-33.

42. Ruan X. Chinese Society of Gynecological Endocrinology affiliated to the International Society of Gynecological Endocrinology Guideline for Ovarian Tissue Cryopreservation and Transplantation. Gynecol Endocrinol. 2018;34(12):1005-10.

43. Ruan X, Du J, Korell M, Kong W, Lu D, Jin F, et al. Case report of the first successful cryopreserved ovarian tissue retransplantation in China. Climacteric. 2018;21(6):613-6.

44. Ruan X, Du J, Lu D, Duan W, Jin F, Kong W, et al. First pregnancy in China after ovarian tissue transplantation to prevent premature ovarian insufficiency. Climacteric 2021: Online ahead of print.

45. Dolmans MM, von Wolff M, Poirot C, Diaz-Garcia C, Cacciottola L, Boissel $\mathrm{N}$, et al. Transplantation of cryopreserved ovarian tissue in a series of 285 women: a review of five leading European centers. Fertil Steril. 2021;115(5):1102-15.

46. Plichta JK, Rai U, Tang R, Coopey SB, Buckley JM, Gadd MA, et al. Factors Associated with Recurrence Rates and Long-Term Survival in Women Diagnosed with Breast Cancer Ages 40 and Younger. Ann Surg Oncol. 2016;23(10):3212-20.

47. Arvold ND, Taghian AG, Niemierko A, Raad RFA, Sreedhara M, Nguyen $\mathrm{PL}$, et al. age, breast cancer subtype approximation, and local recurrence after breast-conserving therapy. J Clin Oncol. 2011:29(29):3885-91.

48. Bartelink H, Horiot JC, Poortmans P, Struikmans H, Van den Bogaert W, Barillot I, et al. Recurrence rates after treatment of breast cancer with standard radiotherapy with or without additional radiation. N Engl J Med. 2001;345(19):1378-87.

\section{Publisher's Note}

Springer Nature remains neutral with regard to jurisdictional claims in published maps and institutional affiliations. 